\title{
Self-rated health and perceived violence in the neighborhood is heterogeneous between young women and men
}

\author{
Aline Almeida Bentes ${ }^{1,2^{*}}$, Cibele Comini César ${ }^{1,2}$, César Coelho Xavier ${ }^{2,3}$, Waleska Teixeira Caiaffa ${ }^{2}$ \\ and Fernando Augusto Proietti ${ }^{1,3}$
}

\begin{abstract}
Background: Self-rated health $(\mathrm{SRH})$ is the general perception of an individual's own health and a key indicator to measure health in population-based studies. Few studies have examined the association between perceived urban violence and SRH among young adults. There were an estimated 475,000 deaths in 2012 as a result of homicide on the world. Sixty percent of these deaths occurred among males aged 15-44 years, making homicide the third leading cause of death for this population group. This study aimed to determine and quantify the association between sexspecific perception of violence in the neighborhood and SRH among young adults.
\end{abstract}

Methods: Participants included 955 young adults (18-29 years) residing in Belo Horizonte, Minas Gerais, Brazil between 2008 and 2009. Logistic regression analysis was used to estimate the strength of the associations. The perceived urban violence score was constructed from variables that assessed the respondents' insecurity and perception of fear and danger of suffering some form of violence in the neighborhood using exploratory factor analysis.

Results: $18,3 \%$ of respondents rated their health as fair/ poor/very poor. Among women, fair/ poor/very poor SRH was associated with age between 25 and 29 years, low socioeconomic status score, being dissatisfied with weight, not exercising regularly, not having a healthy diet, and having some chronic disease. Men who rated their health as fair/poor/very poor more frequently smoked, were dissatisfied with their weight, did not exercise regularly, consumed fewer fruits and vegetables, and had some chronic disease compared to men who rated their health as very good/good. In the final model, after adjusting for confounding variables, perceived violence in the neighborhood was associated with poor SRH in young women only $(\mathrm{OR}=1.52 ; 95 \% \mathrm{Cl}$ : 1.04-2.21).

Conclusion: The results indicate that public and health policies should implement interventions on the neighborhood physical and social environment to improve the perception of safety and have a positive impact on people's health, especially women.

Keywords: Self-rated health, Perceived urban violence, Young adults (18-29 years), Urban population health

\section{Background}

Urban violence is one of the major causes of death and hospitalization among young adults (18-29 years) in several countries [1]. There were an estimated 475,000 deaths in 2012 as a result of homicide on the world. Sixty percent of these deaths occurred among males aged 15-44 years,

\footnotetext{
* Correspondence: alinebentes2000@gmail.com

${ }^{1}$ Centro de Pesquisas René Rachou, Fundação Oswaldo Cruz, Av. Augusto de Lima 1715, Belo Horizonte, MG 30190-002, Brasil

${ }^{2}$ Federal University of Minas Gerais, Av. Prof. Alfredo Balena, 190, Belo

Horizonte Cep 30130-100, MG, Brasil

Full list of author information is available at the end of the article
}

making homicide the third leading cause of death for this population group [1]. Within low- and middle income countries, the highest estimated rate of homicide occurs in the Region of the Americas, with 28.5 homicides per 100,000 population, followed by the African Region with a rate of 10.9 homicides per 100,000 population [1]. Fatal violence is not evenly distributed among sex and age groups. The highest estimated rate of homicide in the world is found among males aged 15-29 years (18.2 per $100,000)[1]$. 
In Brazil, the exposure to violence reveals a negative experience that has already affected an entire generation of young people: a recent survey by the Brazil Health Department indicated that $51.0 \%$ of young adults aged 18-29 years across all states and social strata in small, medium, and large cities have lost a close person in a violent way [2]. Nevertheless, deaths are only a fraction of the health and social burden arising from violence. In a nationally representative study of violence-related injury cases presenting at emergency departments during a 1-month period in Brazil, there were 4835 cases of violence related injury, of which $91 \%$ were victims of interpersonal violence and $9 \%$ were the result of self-directed violence. More than half of the victims (55\%) were also young, aged 10-29 years [1].

Perceived urban violence has been generally defined as a negative emotional reaction to crime and includes reactions or attitudes such as avoiding public places, certain streets, going out at night, or engaging in leisure or sport activities in the neighborhood [3-5]. Structural characteristics such as physical and social disorder, low degree of social integration, urban segregation, and high crime rates in the neighborhood raise fear and anxiety levels among residents of certain urban areas leading to greater perceived violence and worse self-rated health (SRH) [3, 4].

SRH refers to the general perception of an individual's own health and is one of the indicators most commonly used to measure the health of population groups in epidemiological studies [6-8]. Self-rating of health results from a cognitive process involving objective, subjective, and contextual aspects, i.e., even though it is an individual's response, it is based on his/her physical, social, and cultural environment $[6,9]$. Self-rated health has been identified by the American Institute of Medicine as one of the $20 \mathrm{key}$ indicators to measure health in population-based studies [10]. In cohort studies, SRH is a strong predictor of morbidity and mortality $[7,8,11]$.

Sex is one of several well-established independent determinants of SRH. In fact, women usually report worse SRH than men, especially at younger ages [12]. Consistently, a study conducted in Belo Horizonte, Minas Gerais, Brazil in 2013 evaluated the relationship between the physical and social environment and SRH in 4048 adults 18 years and older from a large urban center and showed that women were $38.0 \%$ more likely than men to rate their health as poor [12].

Nevertheless, knowledge about SRH in young adults (1829 years) is still limited and to better understand the determinants of SRH in young adults it is important to examine their historical, socioeconomic and spatial context.

Diez-Roux and Mair in extensive literature review of neighborhood health proposes a theoretical model that describes how the physical and social characteristics of the neighborhood interrelate and affect people's health [13]. Figure 1 summarizes how individual characteristics, behavioral mediators and stress also influence and are influenced by the physical environment and social aspects of neighborhood modifying health and SRH [13].

A study conducted in Illinois, USA, in 1995, which evaluated 2482 adults, found that residents of poor neighborhoods reported worse self-rated health, worse functional performance, and more chronic illnesses than neighborhood residents with greater advantages [14]. This association was mediated by the perception of physical disorganization such as abandoned buildings, noise, graffiti, vandalism, filth, disrepair and greater perception of fear in the neighborhood [14].

A survey made in 2004 with 1504 adults (18 years and over) were residing in Texas found that perceptions of neighborhood disorder may increase the risk of obesity by elevating levels of psychological distress, which, in turn, leads to chronic activation of the physiological stress response [15]. The citizens perceived the neighborhood as an unsafe, dirty and noisy place raised the levels of anxiety and depression of the residents and was associated with poorer quality in diet and obesity [15]. In this study not being satisfied with weight, not eating properly and not performing physical activities was also associated with worse self-rated health in young adults of both sexes.

A multi-center study conducted in six low- and middleincome countries consistently demonstrated that living in impoverished neighborhoods with greater social and physical disorganization where there is greater perception of urban violence is associated with greater psychological stress and numerous sleep problems [16]. Recent studies suggest that living in neighborhoods with greater physical and social disorganization is associated with poorer physical and mental health, poor self-rated health and depression [17-19]. It is possible that sleep quality is a mediating pathway that helps to explain the association between perceived urban violence and poor health.

A national health survey conducted in Denmark in 2000 with 12,028 adults (16+ years) evaluated the associations between violence, SRH and self-reported morbidity [20]. The authors observed that men aged 16-24 years were more likely to have experienced physical violence than women of the same age $(\mathrm{OR}=3.20,95 \% \mathrm{CI}=2.30$ 4.20). Female victims of physical violence were significantly more likely to rate their health as poor $(\mathrm{OR}=2.02,95 \%$ $\mathrm{CI}=1.41-2.89)$ and to report anxiety $(\mathrm{OR}=2.14,95 \%$ $\mathrm{CI}=1.35-3.37)$, depression $(\mathrm{OR}=2.36,95 \% \mathrm{CI}=1.55-$ $3.60)$, and stomach ache $(\mathrm{OR}=1.58,95 \% \mathrm{CI}=1.01-$ 2.47) than female non-victims. Associations between physical violence and poor self-rated health and selfreported morbidity were statistically associates for women, but not for men [20]. 


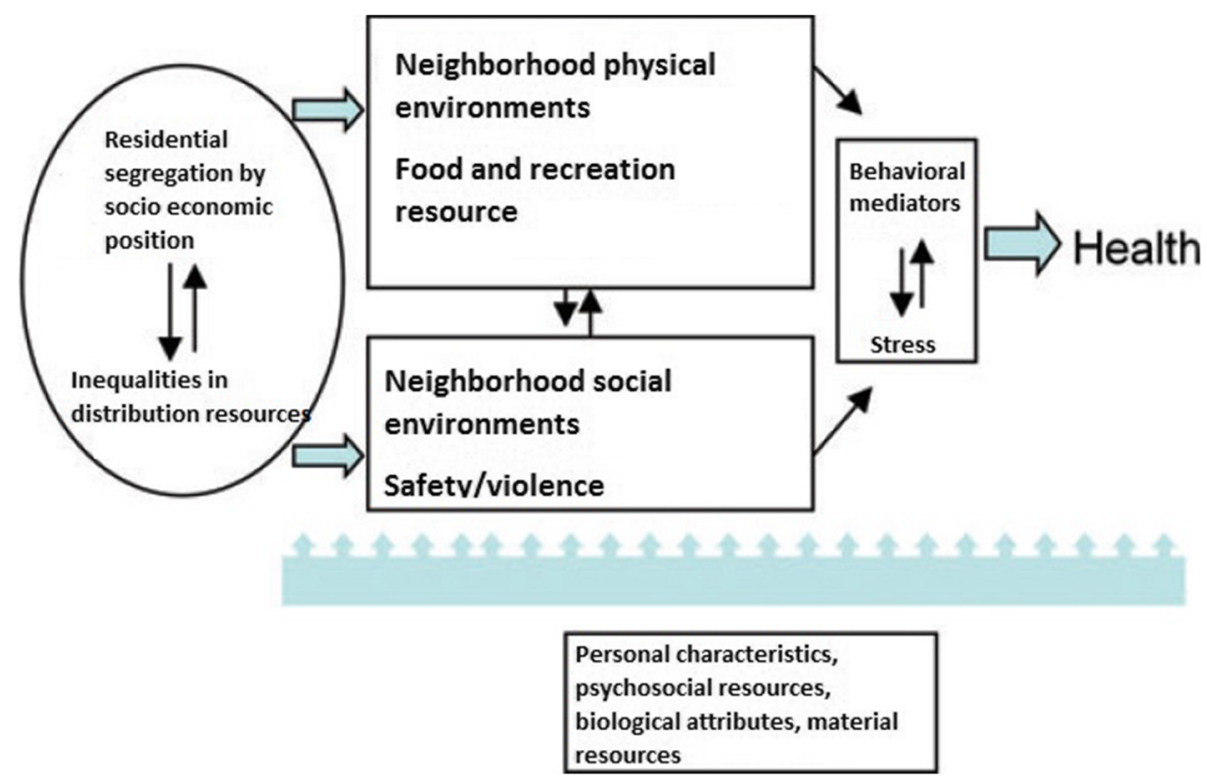

Fig. 1 Schematic representation of the contribution of neighborhood environment to health, adapt from Diez Roux and Mair [13]

A longitudinal study of 8224 U.S. youths 12 to 18 years old at baseline reported that the risk for poor SRH was 4.6 times greater among subjects who were exposed to violence $(\mathrm{OR}=4.63,95 \% \mathrm{CI}=3.06-6.99)$ [21]. Having witnessed gun violence, being threatened at school, bullied repeatedly, or a victim of crime were independently and significantly associated with poor SRH. Additionally, the prevalence of fair/poor SRH was higher among female (56.0\%), low-income (32.0\%), and African-American youths (39.0\%) [21].

The present study aimed to determine and quantify the association between sex specific perception of violence in the neighborhood and SRH among young adults. We hypothesized that there is heterogeneity in the impact of the perception of violence on self-rated health for men and women.

\section{Methods}

This study assessed data from a population-based health survey conducted by the Belo Horizonte Urban Health Observatory (OSUBH) of the Federal University of Minas Gerais (UFMG) between 2008 and 2009 in two - Barreiro and Oeste - of the nine health districts of the city. Belo Horizonte (2.513.451 inhabitants) is the capital of Minas Gerais State located in southeast Brazil and the main city of the Belo Horizonte Metropolitan Area (5.873.841 inhabitants) [22]. The estimated population of each district is approximately 250,000.

The study area was divided into strata according to the health vulnerability index (HVI), developed by the Belo Horizonte City Health Department. The HIV is a summary measure that estimates the inequalities in the epidemiological profile of different social groups within the census tracts. It includes the following components: sanitation, housing, education, income, and health [22].

In each HVI stratum, selection was performed using a three-stage sampling methodology: census tract, address (residence), and resident (one adult). In total, 150 tracts were selected. Within each census tract, a simple random sample of household addresses registered in the database of the Municipality of Belo Horizonte was taken. Next, one adult resident (18 years or older) was drawn using a random number table.

At the end of the sampling process, 5.436 households had been selected. After being informed about the objectives of the study, residents who were drawn were invited to participate and sign a consent form. In total, 4.048 adults were interviewed with a refusal rate of $25.0 \%$. For this study, we selected only young adults between the ages of 18 and 29 years, representing 955 participants. All participants answered a face-to-face questionnaire administered by trained interviewers. The questionnaire was composed of six modules: household, sociodemographic factors, health, mobility, social determinants of health, lifestyle and behaviors.

Detailed information about the SBH survey methodology can be found in Camargos et al. [23] and Friche et al. [22, 24].

The study was approved by the Research Ethics Committee of the Federal University of Minas Gerais (UFMG), Brazil, under protocol numbers ETCI 253/006 and ETCI 017/07. 


\section{Variables}

\section{Response variable}

Self-rated health was assessed by the question "In general, how would you rate your health?", with five responses on a five-category scale: "very good", "good", "fair", "poor", or "very poor". Responses were later categorized for analysis as fair/poor/very poor, and very good/good (reference category).

\section{Variable of interest}

The explanatory variable of interest was perceived urban violence, defined as a negative emotional reaction to crime, a social phenomenon that reduces social interaction and mutual trust among residents, causing a decline in the quality of life in the community or neighborhood [3-5].

The perceived urban violence score was constructed using the variables to assess the respondents' perception of fear, danger, and insecurity of suffering some form of violence in the neighborhood. Participants were asked the following questions: What is the risk of being (1) personally threatened, robbed/mugged; (2) assaulted or threatened with aggression; (3) abducted (kidnapped); (4) hit by a stray bullet; (5) seriously injured or killed; and (6) a victim of police violence. Respondents rated the risk as very high, high, low, or very low. The perceived urban violence score was calculated using the principal components method and ranged from 1.21 to 4.85 (mean \pm $\mathrm{sd}=2.13 \pm 0.69)$ for women and 1.21 to $4.65(2.32 \pm 0.74)$ for men.

Potential confounding variables were divided into the following categories:

A) Time residing in the neighborhood in years

B) Demographics: age (18-24 and 25-29 years); sex and marital status: married/living together or divorced/separated and single

C) Schooling: able to read/primary school equivalency; 1st-4th grades not completed; 1 st-4th grades completed; 5 th-8th grades not completed; 5 th-8th grades completed; high school not completed; high school graduate/technical school/attended university; university graduate; post-undergraduate studies.

D) Socioeconomic: socioeconomic position score (SPS), detailed below;

E) Lifestyle and behaviors: 1) smoking: current smoker and non-smoker/former smoker; 2) alcohol consumption: non-drinker, moderate consumption (1-2 times a week and less than five drinks per day), or excessive consumption ( $\geq$ three times a week or more than five drinks per day); 3) consumption of fruits and vegetables: defined as consumption of at least one portion 5 days a week for the past 12 months, yes/ no; 4) physical activity: physical activity during leisure time $\geq 30 \mathrm{~min} /$ day and physical activity during leisure time $<30 \mathrm{~min} /$ day $(1 \%$ of respondents who performed physical activity exercised for $<30 \mathrm{~min} /$ day).

F) Health condition: 1) whether he/she is satisfied with their own weight: yes/ no; 2) report of chronic disease: yes/no, detailed below;

The socioeconomic position score was constructed using 13 indicators: number of residents per bedroom; housing tenure (rented, owned, loaned, other); and presence or absence (yes/no) of the following items in the household: DVD player, videocassette recorder; cable TV subscription; microwave oven; automatic washing machine; house maid; semi-automatic washing machine; motorcycle; newspaper and/or magazine subscription; computer; internet access; motorcycle; car. The scores were calculated using the principal components method (range: 0-3.39) and were divided into quintiles. Higher scores indicate higher socioeconomic position [6].

The variable self-reported chronic disease included the following illnesses: hypertension, diabetes, asthma, bronchitis, depression, migraine, epilepsy, cancer, chronic digestive disease (ulcer, gastritis), and mental illness (schizophrenia, psychosis, anxiety disorder, bipolar disorder, obsessive-compulsive disorder, panic disorder, anorexia, bulimia). Participants were classified as having a chronic disease if they reported having at least one of the above conditions.

\section{Statistical analyses}

The perceived urban violence score was constructed from variables that assessed the respondents' insecurity and perception of fear and danger of suffering some form of violence in the neighborhood using exploratory factor analysis. Factor analysis is a data reduction method, which is based on the assumption that highly correlated observed variables (indicators, items, or manifest variables) reflect the action of one or more (unobservable) latent variables or factors [25]. By estimating the latent factors, we were able to account for all or most of the variability generated by the observed variables using a few factors $[25,26]$. Because variables were ordinal, we used the polychoric correlation matrix in factor analysis to calculate the scores [26].

Variables with a $p$ value $\leq 0.2$ on univariate analysis were included in the multivariate analysis. The sampling design was incorporated into the analysis using Stata 'svy' command. The strength of the associations was estimated by the odds ratios (OR) and 95\% confidence intervals.

To construct the final model, we adopted the hierarchical approach, a sequential process in which the variables entry into the analysis in blocks following the theoretical model presented in Fig. 1 [13]. We use this model to better evaluate how perceived urban violence is associated with health 
self-assessment, hierarchically adjusting the confounding factors, understanding that they are moderators of this association [27]. Nested models were evaluated using the Wald test. The adjustment of the final model was assessed by the Hosmer Lemeshow test, considering the sampling design.

The evaluated models were: model 1: Urban Violence Perceived Score.

Model 2: model 1 plus years residing in the neighborhood.

Model 3: model 2 plus age, sex (for all participants only) and marital status.

Model 4: model 3 plus schooling and socioeconomic position score.

Model 5: model 4 plus alcohol consumption, smoking, healthy diet and physical activity.

Model 6: model 5 plus satisfied with his/her own weight and reporting of chronic diseases.

All analyses were performed using Stata software version 12.0 (StataCorp, College Station, TX, USA).

\section{Results}

Of the 955 participants, $54.4 \%$ were women. Among the women, $79.7 \%$ rated their health as very good/good whereas among men this classification was reported by $83.9 \%$. The estimated urban violence score ranged from 1.21 to 4.85 (mean \pm SD: $2.32 \pm 0.77$ ) for women and 1.21 to 4.65 $(2.14 \pm 0.70)$ for men. In addition, $54.8 \%$ of the participants were aged $18-24$ years, $32.7 \%$ were married or living in a stable union: $38,34 \%$ of the women and $25,90 \%$ of the men.

Nearly three-fourths (73.3\%) of the respondents had not completed high school whereas $9.3 \%$ of women and $7.1 \%$ of men had university graduate/post-undergraduate studies. Regard the SPS quintiles $47.4 \%$ of the women were in the two lower quintiles (1 and 2) and $35.5 \%$ in the two upper quintiles ( 4 and 5). For the males the percentages were $34.7 \%$ in the two lower quintiles and $42.9 \%$ in the upper two quintiles (Table 1).

Roughly $36.3 \%$ of respondents reported regular alcohol consumption and $34.6 \%$ of the men and $16.4 \%$ of the women reported excessive alcohol consumption ( $\geq$ three times a week or $>$ five drinks per day). $18.4 \%$ of men and $14.3 \%$ of women were smokers.

Among women, $62.6 \%$ reported not being satisfied with their weight, $74.2 \%$ did not exercise regularly and $64.4 \%$ did not have a healthy diet. For the men whereas $48.8 \%$ were not satisfied with their weight, $44.5 \%$ were not physical active, and $70.4 \%$ did not have a healthy diet. The presence of at least one chronic disease was reported by $35.5 \%$ of respondents, of which $44,9 \%$ were women and $24,4 \%$ were men.

Over fifty $(62.5 \%)$ of respondents reported residing in the same neighborhood for over 10 years, $58.8 \%$ of women and $67.0 \%$ of men (Table 1 ).
Table 2 shows the results of univariate analysis by sex. Among women, fair poor/very poor SRH was associated with age between 25 and 29 years, be married or living in a stable union, low SPS, being dissatisfied with their weight, not exercising regularly, not having a healthy diet, and having some chronic disease.

Men who rated their health as fair/poor/very poor more frequently smoked, were dissatisfied with their weight, did not exercise regularly, consumed fewer fruits and vegetables, and had some chronic disease compared to men who rated their health as very good/good.

In Table 3 are shown each of the hierarchical models. For all participants and males, after accounting for all potential confounding variables (Model 6), perceived urban violence was not associated with SRH. For the women the hierarchical models from 3 to 6 shows association between perceived violence in the neighborhood and fair/poor/very poor SRH. An unit increase in the perceived violence in the neighborhood score increased by $52 \%$ the odds of women rating their health as fair, poor or very poor, after accounting for all potential confounding variable $(\mathrm{OR}=1.52 ; 95 \% \mathrm{CI}$ : 1.04-2.21, Model 6).

\section{Discussion}

Our results indicate that perceived violence in the neighborhood is associated with fair/poor/very poor SRH in young women; however, we did not find the same association for young males.

Urban violence is a phenomenon that demands a multifaceted, inter-sectorial, and interdisciplinary approach, related to individuals, groups, classes, and institutions, which in their relations employ different methods and means of coercion and annihilation of people. Living in large cities has implications for people's lives and on the social determinants that operate through various process $[13,28]$.

Violence, increased neighborhood crime, and weaker social cohesion are also dynamically linked to the characteristics of the physical and social environment, increasing stress levels and changing people's behavior, leading to worsening health and poor SRH. Thus, both physical and social environment as well as behavioral characteristics can weaken social ties and increase violence [13, 14, 16, 19].

The magnitude, nature, and impact of urban violence on health differ greatly for men and women. Violence against women has been associated with worse SRH, worse quality of life, gynecological symptoms, depression, chronic pain, post traumatic stress disorder and substance abuse [28-30]. A 2006 Swedish study evaluated 34,707 women in two age groups: $18-29$ years and 30-44 years, with results similar to our study, reporting an association between the risk of some form of violence in the 
Table 1 Frequency distribution by sex of self-rated health (SRH) and selected variables among 955 young adults (18-29 years). Belo Horizonte Health Study, Brazil, 2008-2009

\begin{tabular}{|c|c|c|c|}
\hline Variable & $\begin{array}{l}\text { Total } \\
N(\%)\end{array}$ & $\begin{array}{l}\text { Females } \\
N(\%)\end{array}$ & $\begin{array}{l}\text { Males } \\
N(\%)\end{array}$ \\
\hline Participants & $955(100)$ & $519(54,35)$ & $436(45,65)$ \\
\hline \multicolumn{4}{|l|}{ Self-rated health } \\
\hline Very good/good & $779(81,70)$ & $413(79,70)$ & $366(83,90)$ \\
\hline Fair/poor/very poor & $175(18,30)$ & $105(20,30)$ & $70(16,10)$ \\
\hline Perceived violence score & 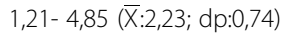 & $1,21-4,85(\bar{X}: 2,32 ; \mathrm{dp}: 0,77)$ & $1,21-4,65(\bar{X}: 2,14 ; \mathrm{dp}: 0,70)$ \\
\hline Time residing in the same neighborhood & $(\bar{X}: 13,81 ; \mathrm{dp}: 9,02)$ & $(\overline{\mathrm{X}}: 13,05 ; \mathrm{dp}: 8,92)$ & $(\overline{\mathrm{X}}: 14,72 ; \mathrm{dp}: 9,06)$ \\
\hline \multicolumn{4}{|l|}{ Age (years): } \\
\hline $18-24$ & $523(54,80)$ & $268(51,60)$ & $255(58,50)$ \\
\hline $25-29$ & $432(45,20)$ & $251(48,40)$ & $181(41,50)$ \\
\hline \multicolumn{4}{|l|}{ Marital state } \\
\hline Married/living together & $312(32,67)$ & $199(38,34)$ & $113(25,90)$ \\
\hline Single, divorced/separated & $643(67,33)$ & $320(61,66)$ & $323(74,10)$ \\
\hline \multicolumn{4}{|l|}{ Educational level } \\
\hline $\begin{array}{l}\text { Able to read, primary school, } 1 \text { st- } 4 \text { th grades not completed, } \\
1 \text { st-4th grade completed, } 5 \text { th-8th grade not completed }\end{array}$ & $216(22,64)$ & $123(23,70)$ & $93(22,20)$ \\
\hline 5th-8th grade completed, high school not completed & $483(50,63)$ & $261(50,40)$ & $222(50,10)$ \\
\hline High school graduate, technical school, attended university & $176(18,45)$ & $86(16,60)$ & $90(20,60)$ \\
\hline University graduate, post-undergraduate studies & $79(8,28)$ & $48(9,30)$ & $31(7,10)$ \\
\hline \multicolumn{4}{|l|}{ Socioeconomic position score ${ }^{a}$} \\
\hline 1 & $213(22,40)$ & $136(26,20)$ & $77(17,70)$ \\
\hline 2 & $184(19,30)$ & $110(21,20)$ & $74(17,00)$ \\
\hline 3 & $185(19,40)$ & $89(17,20)$ & $96(22,00)$ \\
\hline 4 & $193(20,30)$ & $95(18,30)$ & $98(22,50)$ \\
\hline 5 & $178(18,70)$ & $89(17,20)$ & $89(20,40)$ \\
\hline \multicolumn{4}{|l|}{ Alcohol consumption } \\
\hline Non-drinker & $608(63,67)$ & $378(72,80)$ & $230(52,70)$ \\
\hline Moderate consumption & $111(11,62)$ & $56(10,80)$ & $55(12,60)$ \\
\hline Excessive consumption & $236(24,71)$ & $85(16,40)$ & $151(34,60)$ \\
\hline \multicolumn{4}{|l|}{ Smoking } \\
\hline Yes & $154(16,10)$ & $74(14,30)$ & $80(18,40)$ \\
\hline No & $801(83,90)$ & $445(85,70)$ & $356(81,60)$ \\
\hline \multicolumn{4}{|l|}{ Satisfied with his/her own weight } \\
\hline Yes & $417(43,70)$ & $194(37,38)$ & $223(51,20)$ \\
\hline No & $538(57,30)$ & $325(62,62)$ & $213(48,80)$ \\
\hline \multicolumn{4}{|l|}{ Physical activity } \\
\hline Yes & $376(39,40)$ & $134(25,80)$ & $242(55,50)$ \\
\hline No & $579(60,60)$ & $385(74,20)$ & $194(44,50)$ \\
\hline \multicolumn{4}{|l|}{ Healthy diet } \\
\hline Yes & $314(32,90)$ & $185(35,65)$ & $129(29,60)$ \\
\hline No & $641(67,10)$ & $334(64,35)$ & $307(70,40)$ \\
\hline \multicolumn{4}{|l|}{ Chronic disease } \\
\hline Yes & $339(35,53)$ & $233(44,89)$ & $106(24,37)$ \\
\hline No & $615(64,47)$ & $286(55,11)$ & $329(75,63)$ \\
\hline
\end{tabular}

Missing data: chronic disease $(n=7)$, SRH $(n=1)$, education level $(n=1)$, and socioeconomic score $(n=2){ }^{\text {a }}$. SPS: Score ranging from 0 to 3.39 ; higher number of assets $=$ higher score 
Table 2 Odds ratio and confidence intervals for the sex-specific association between selected variables and self-rated health $(\mathrm{SRH})$ among 955 young adults (18-29 years). Belo Horizonte Health Study (BHS), Belo Horizonte, Brazil, 2008 -2009. Univariate analysis

\begin{tabular}{|c|c|c|}
\hline Variable & $\begin{array}{l}\text { SRH Females } \\
\text { OR }(95 \% \mathrm{Cl})\end{array}$ & $\begin{array}{l}\text { SRH Males } \\
\text { OR }(95 \% \mathrm{Cl})\end{array}$ \\
\hline Perceived violence score & $1,46(0,98-2,17)$ & $1,27(0,79-2,07)$ \\
\hline $\begin{array}{l}\text { Time residing in the same } \\
\text { neighborhood }\end{array}$ & $0,98(0,95-1,02)$ & $1,00(0,97-1,04)$ \\
\hline \multicolumn{3}{|l|}{ Age (years): } \\
\hline $18-24$ & 1,00 & 1,00 \\
\hline $25-29$ & $0,54(0,31-0,96)$ & $0,74(0,38-1,44)$ \\
\hline \multicolumn{3}{|l|}{ Marital state } \\
\hline Single, divorced/separated & 1,00 & 1,00 \\
\hline Married/living together & $1,93(1,10-3,51)$ & $1,74(0,93-3,30)$ \\
\hline \multicolumn{3}{|l|}{ Educational level } \\
\hline $\begin{array}{l}\text { Able to read, primary school, } \\
\text { 1st-4th grades not completed, } \\
\text { 1st-4th grade completed, } \\
\text { 5th-8th grade not completed }\end{array}$ & 1,00 & 1,00 \\
\hline $\begin{array}{l}\text { 5th-8th grade completed, } \\
\text { high school not completed }\end{array}$ & $0,66(0,33-1,33)$ & $0,52(0,24-1,12)$ \\
\hline $\begin{array}{l}\text { High school graduate, } \\
\text { technical school, attended university }\end{array}$ & $0,55(0,23-1,26)$ & $0,51(0,19-1370$ \\
\hline $\begin{array}{l}\text { University graduate, } \\
\text { post-undergraduate studies }\end{array}$ & $0,04(0,01-0,18)$ & $0,71(0,11-4,54)$ \\
\hline \multicolumn{3}{|l|}{ Socioeconomic position score ${ }^{a}$} \\
\hline 1 & 1,00 & 1,00 \\
\hline 2 & $0,46(0,23-0,93)$ & $0,62(0,02-1,68)$ \\
\hline 3 & $0,29(0,13-0,66)$ & $0,44(0,18-1,10)$ \\
\hline 4 & $0,27(0,11-0,63)$ & $0,23(0,08-0,63)$ \\
\hline 5 & $0,15(0,05-0,45)$ & $0,43(0,15-1,21)$ \\
\hline \multicolumn{3}{|l|}{ Alcohol consumption } \\
\hline No & 1,00 & 1,00 \\
\hline Yes & $1,05(0,73-1,51)$ & $1,24(0,85-1,80)$ \\
\hline \multicolumn{3}{|l|}{ Smoking } \\
\hline No & 1,00 & 1,00 \\
\hline Yes & $1,41(0,65-3,03)$ & $3,81(1,74-8,35)$ \\
\hline \multicolumn{3}{|l|}{ Healthy diet } \\
\hline No & 1,00 & 1,00 \\
\hline Yes & $0,35(0,18-0,69)$ & $0,43(0,20-0,94)$ \\
\hline \multicolumn{3}{|l|}{ Satisfied with his/her own weight } \\
\hline No & 1,00 & 1,00 \\
\hline Yes & $0,40(0,21-0,77)$ & $0,39(0,19-0,77)$ \\
\hline \multicolumn{3}{|l|}{ Physical activity } \\
\hline No & 1,00 & 1,00 \\
\hline Yes & $0,51(0,27-0,96)$ & $0,41(0,20-0,84)$ \\
\hline \multicolumn{3}{|l|}{ Chronic disease } \\
\hline No & 1,00 & 1,00 \\
\hline Yes & $2,16(1,24-3,77)$ & $4,10(1,98-8,50)$ \\
\hline
\end{tabular}

a Socioeconomic position score score ranging from 0-3.39: highest number of assets $=$ highest score
Table 3 Perceived urban violence on health self-assessment in each of the hierarchical models for all, females and males participants for 955 young adults (18-29 years). Belo Horizonte Health Study, Belo Horizonte, Brazil, 2008-2009

\begin{tabular}{llll}
\hline Models & $\begin{array}{l}\text { SRH Total } \\
\text { OR }(95 \% \mathrm{Cl})\end{array}$ & $\begin{array}{l}\text { SRH Females } \\
\text { OR }(95 \% \mathrm{Cl})\end{array}$ & $\begin{array}{l}\text { SRH Males } \\
\text { OR }(95 \% \mathrm{Cl})\end{array}$ \\
\hline Model 1 & $1,40(1,05-1,87)$ & $1,46(0,99-2,16)$ & $1,27(0,79-2,03)$ \\
Model 2 & $1,37(1,02-1,84)$ & $1,47(1,00-2,17)$ & $1,15(0,72-1,83)$ \\
Model 3 & $1,38(1,03-1,86)$ & $1,54(1,06-2,25)$ & $1,15(0,71-1,85)$ \\
Model 4 & $1,28(0,96-1,71)$ & $1,47(1,04-2,09)$ & $1,05(0,64-1,73)$ \\
Model 5 & $1,27(0,94-1,72)$ & $1,47(1,02-2,12)$ & $1,02(0,59-1,75)$ \\
Model 6 & $1,28(0,94-1,74)$ & $1,52(1,04-2,21)$ & $0,94(0,52-1,68)$ \\
\hline
\end{tabular}

Model 1: Urban Violence Perceived Score

Model 2: Model 1 plus years residing in the neighborhood

Model 3: Model 2 plus age, sex (for all participants only) and marital status

Model 4: Model 3 plus schooling and socioeconomic position score

Model 5: Model 4 plus alcohol consumption, smoking, healthy diet and physical activity

Model 6: Model 5 plus satisfied with his/her own weight and reporting of chronic diseases

neighborhood and worst SRH in both age groups. This study also found synergistic effect between violence and low socioeconomic status worsening the selfassessment of health [29].

Research evidence suggests that gender based violence can be concentrated at the neighborhood level, especially in disadvantaged, vulnerable urban settings. Disadvantaged urban settings can exacerbate underlying gender-based power disparities, subjecting young women to intensive harassment, pressure for early sexual activity, and a pervasive threat of sexual and physical violence [30]. Large populated neighborhoods characterized by weak social ties and low collective efficacy can also increase the risk of violence [29-31].

There are possible sociological explanations for the results observed in our study. Some studies argue that women are taught, from an early age, to take care of people and family and to be more empathetic towards community suffering, whereas men are encouraged to be aggressive and competitive [31,32]. These differences in the socialization process predispose women to internalize their difficulties, resulting in an increased incidence of depression, anxiety, and possibly poor self-rating of health. Conversely, men exposed to community violence tend to develop aggressive behaviors and are more prone to crime $[31,32]$.

No association between perceived urban violence and SRH may also reflect adaptation by young men growing up exposed to neighborhood violence [32]. Some researchers suggest that male youths who are chronically exposed to community violence may become desensitized and suppress feelings of sadness or anxiety [33, 34]. Male youths may develop initial internalizing symptoms in reaction to new or unusual exposure to violence, but 
over time their symptoms might be expected to abate [33]. Thus, rather than concluding that young males do not experience symptoms or that they minimize their response to a violent event, it is possible that there are fundamental gender differences in the type of response [34]. It appears that moderating factors may mitigate the conditions under which violence exposure in youth leads to adverse outcomes [35].

The Belo Horizonte Health Study was not originally designed to specifically investigate young adults. Although consistent with the literature, our study had not found an association between perceived violence in the neighborhood and poor self-reported health among young men. We cannot rule out the study sample size and low power to estimate this association. However, this study is of great relevance because it was the first study to evaluate the association between sex-specific perception of violence in the neighborhood and SRH among young adults in a middle income country.

This study has several strengths. Few studies have examined the association between perceived urban violence and SRH among young adults, despite the relevance of the issue especially when violence is one of the leading causes of death among young people in many countries. Several steps were taken to avoid potential biases, including reliability assessment of the instruments used, use of standard procedures and equipment, extensive training of field personnel in addition to intensive activities with the community to encourage participation in the study. Thus, the internal validity and quality of information were ensured [24].

\section{Conclusions}

We showed that perceived violence in the neighborhood was associated with poor SRH in women, even after adjusting for several individual attributes. Even though the mechanisms responsible for this association have not been clearly elucidated, the results of this study indicate that public and health policies should implement interventions on the physical and social environment of the district or neighborhood that improve the perception of safety and have a positive impact on people's health, especially women.

\footnotetext{
Acknowledgements

The authors thank all partners for contributing to the development of the conceptual model and the content of this article.

National Council of Scientific and Technological Development (CNPq), Brazil. Urban Health Observatory, Belo Horizonte, Minas Gerais.

Federal University of Minas Gerais.

Ministry of Health Brazil.
}

\section{Funding}

National Council of Scientific and Technological Development (CNPq), Brazil. Urban Health Observatory, Belo Horizonte, Minas Gerais. Federal University of Minas Gerais. Ministry of Health Brazil.

\section{Availability of data and materials}

The datasets used and analyzed during the current study are available from the corresponding author on reasonable request.

\section{Authors' contributions}

$A A B$ contributed to the conception of the study, data interpretation and writing of the article. CCC contributed to data analysis and interpretation, review and approval of the final version. CCX contributed to review and approval of the final version. WTC contributed to the conception of the study, results interpretation, and approval of the final version of the article. FAP contributed to the conception of the project, data analysis, review and approval of the final version of the article. All authors read and approved the final manuscript.

\section{Ethics approval and consent to participate}

The study was approved by the Research Ethics Committee of the Federal University of Minas Gerais (UFMG), Brazil, under protocol numbers ETCI 253/006 and ETCl 017/07. After being informed about the objectives of the study,

residents who were drawn were invited to participate and sign a consent form.

\section{Consent for publication}

Not applicable

\section{Competing interests}

The authors declare that they have no competing interests.

\section{Publisher's Note}

Springer Nature remains neutral with regard to jurisdictional claims in published maps and institutional affiliations.

\section{Author details}

${ }^{1}$ Centro de Pesquisas René Rachou, Fundação Oswaldo Cruz, Av. Augusto de Lima 1715, Belo Horizonte, MG 30190-002, Brasil. ²Federal University of Minas Gerais, Av. Prof. Alfredo Balena, 190, Belo Horizonte Cep 30130-100, MG, Brasil. ${ }^{3}$ FASEH: Faculdade da Saúde e Ecologia Humana, Rua Sao Paulo, 958, Vespasiano Cep 33200-000, MG, Brasil.

Received: 18 January 2017 Accepted: 29 November 2017

Published online: 19 December 2017

\section{References}

1. Mikton CR, Butchart A, Dahlberg LL, Krug EG. Global status report on violence prevention 2014. Am J Prev Med. 2016;50(5):652-9. doi:10.1016/j. amepre.2015.10.007.

2. Jaen-Varas D, Mari JJ, Coutinho ES, Andreoli SB, Quintana Ml, de Mello MF, Bressan RA, Ribeiro WS. A cross-sectional study to compare levels of psychiatric morbidity between young people and adults exposed to violence in a large urban center. BMC Psychiatry. 2016 Jun 7;16:134. doi:10.1186.

3. Sampson RJ, Raudenbush SW, Earls F. Neighborhoods and violent crime: a multilevel study of collective efficacy. Science. 1997;277(5328):918-24.

4. Morenoff JD. Neighborhood mechanisms and the spatial dynamics of birth weight. Am J Sociol. 2003;108:976-1017.

5. Silva BFA, Beato Filho CC. Social ecology of fear: evaluating the association between neighborhood context and fear of crime. R Bras Est Pop. 2013;30:155-70.

6. Jylha M. What is the self-rated health and why does it predict mortality? Toward a unified conceptual model. Soc Sci Med. 2009;69:307-16.

7. Dowd JB, Zajacova A. Does the predictive power of self-rated health for subsequent mortality risk vary by socioeconomic status in the US? Int J Epidemiol. 2007;36:1214-21.

8. Lima-Costa MF, Cesar CC, Chor D, Proietti FA. Self-rated health compared with objectively measured health status as a tool for mortality risk screening in older adults: 10-year follow-up of the Bambuí cohort study of aging. Am J Epidemiol. 2011;175(3):228-35.

9. Fyers PM, Sprangers MAG. Understanding self-rated health. Lancet. 2002;359:187-8.

10. Ishan GJ, Bialek R, Bradburn NM, Fichetenberg C, Gruman J, Holtgrave D, et al. State of the USA health indicators: letter report. Institute of Medicine. Washington, DC: National Academic Press; 2009.

11. Idler EL. Age differences in self-assessments of health: age changes, cohort differences, or survivorship? J Gerontol. 1993;48(6):S289-300. 
12. Rodrigues DE, Cesar CC, Xavier CC, Caiaffa WT, Proietti FA. The place where you live and self-rated health in a large urban area. Cad Saúde Pública. 2015;31:246-56.

13. Diez-Roux AV, Mair C. Neighborhoods and health. Ann N Y Acad Sci. 2010; 1186:125-45.

14. Ross CE, Mirowsky J. Neighborhood disadvantage, disorder, and health. J Health Soc Behav. 2001:258-76.

15. Burdette A, Hill T. An examination of processes linking perceived Neighborhood disorder and obesity. Soc Sci Med. 2008;67:38-46.

16. Hill T, Trinh HN, Wen M, Hale L. Perceived Neighborhood safety and sleep quality: a global analysis of six countries. Sleep Med. 2016;18:56-60.

17. Hale L, Hill T, Friedman E, Nieto J, Galvao L, Engelman C, Malecki K, Peppard P. Perceived Neighborhood quality, sleep quality, and health status: evidence from the survey of the health of Wisconsin. Soc Sci Med. 2013;79:16-22.

18. Hale L, Hill T, Burdette A. Does sleep quality mediate the association between Neighborhood disorder and self-rated health? Prev Med. 2010;51:275-8.

19. Hill T, Ross C, Angel R. Neighborhood disorder, Psychophysiological distress, and health. J Health Soc Behav. 2005;46:170-86.

20. Sundaram V, Helweg-Larsen K, Laursen B, Bjerrgard P. Physical violence, self rated health, and morbidity: is gender significant for victimisation? J Epidemiol Community Health. 2004:58(1):65-70.

21. Boynton-Jarret R, Ryan LM, Berkman LF, Wright RJ. Cumulative violence exposure and self-rated health: longitudinal study of adolescents in the United States. Pediatrics. 2008;122(5):961-70.

22. Caiaffa WT, Almeida MCM, Oliveira CL, Friche AAL, Matos SG, Dias MAS, Cunha MCM, Pessanha E, Proietti FA. The urban environment from the health perspective: the case of Belo Horizonte, Minas Gerais, Brazil. Cad Saúde Pública, Rio de Janeiro. 2005;21(3):958-67.

23. Camargos VP, César CC, Caiaffa WT, Xavier CC, Proeitti FA. Multiple imputation and complete case analysis in logistic regression models: a practical assessment of the impact of incomplete covariate data. Cad Saúde Pública. 2011; 27(12): 2299-2313. doi.org/10.1590/S0102-311X2011001200003.

24. Friche AAL, Diez-Roux AV, César CC, Xavier CC, Proietti FA, Caiaffa WT. Assessing the psychometric and ecometric properties of Neighborhood scales in developing countries: Saúde em Beagá study, Belo Horizonte, Brazil, 2008-2009. J Urban Health. 2013;90(2):246-61.

25. Costello AB, Osborne JW. Best practices in exploratory factor analysis: four recommendations for getting the most from your analysis. Pract Asses Res Eval. 2005;10(7):1-9. Available from: http://pareonline.net/pdf/v10n7.pdf Accessed 15 Feb 2016

26. Suhr DD. Principal Component Analysis vs. Exploratory Factor Analysis. Statistics and Data Analysis. University of Northern Colorado 2005; 203-230. Available from: http://www2.sas.com/proceedings/sugi30/203-30.pdf Accessed 15 Feb 2016.

27. Huo Y, de la Torre J, Mun EY, Kim SY, Ray AE, Jiao Y, White HR. A hierarchical multi-unidimensional IRT approach for analyzing sparse, multi group data for integrative data analysis. Psychometrika. 2015 Sep;80(3):834-55. doi:10.1007.

28. Pedersen PV, Gronbaek M, Curtis T. Associations between deprived life circumstances, wellbeing and self-rated health in a socially marginalized population. Eur J Pub Health. 2012;22(5):647-52.

29. Winnersjö R, Ponce de Leon A, Soares JF, Macassa G. Violence and self-reported health: does individual socioeconomic position matter? J Inj Violence Res. 2012 Jul; 4(2):87-95. doi:10.5249

30. Decker MR, Peitzmeier S, Olumide A, Acharya R, Ojengbede O, Covarrubias L, et al. Prevalence and health impact of intimate partner violence and non-partner sexual violence among female adolescents aged 15 -19 years in vulnerable urban environments: a multi-country study. J Adolesc Health. 2014;55(6):S58-67.

31. Foster JD, Kuperminc GP, Price AW. Gender differences in posttraumatic stress and related symptoms among inner-city minority youth exposed to community violence. J Youth Adoles. 2004:59-69.

32. Fowler PJ, Tompsett CJ, Braciszewski JM, Jacques-Tiura AJ, Baltes BB. Community violence: a meta-analysis on the effect of exposure and mental health outcomes of children and adolescents. Dev Psychopathol. 2009:221:227.

33. Farrell A, Bruce S. Impact of exposure to community violence on violent behavior and emotional distress among urban adolescents. J Clin Child Psychol. 1997;26:2-14.

34. Hanson RF, Borntrager C, Self-Brown S, Kilpatrick DG, Saunders BE, Resnick HS, Amstadter A. Relations among gender, violence exposure, and mental health: the national survey of adolescents. Am J Orthop. 2008 Jul;78(3):313-21. doi:10.1037.

35. Horowitz K, Weine S, Jekel J. PTSD symptoms in urban adolescent girls: compounded community trauma. J Am Acad Child Adolesc Psychiatry. 1995;34:1353-61.

\section{Submit your next manuscript to BioMed Central and we will help you at every step:}

- We accept pre-submission inquiries

- Our selector tool helps you to find the most relevant journal

- We provide round the clock customer support

- Convenient online submission

- Thorough peer review

- Inclusion in PubMed and all major indexing services

- Maximum visibility for your research

Submit your manuscript at www.biomedcentral.com/submit
) Biomed Central 